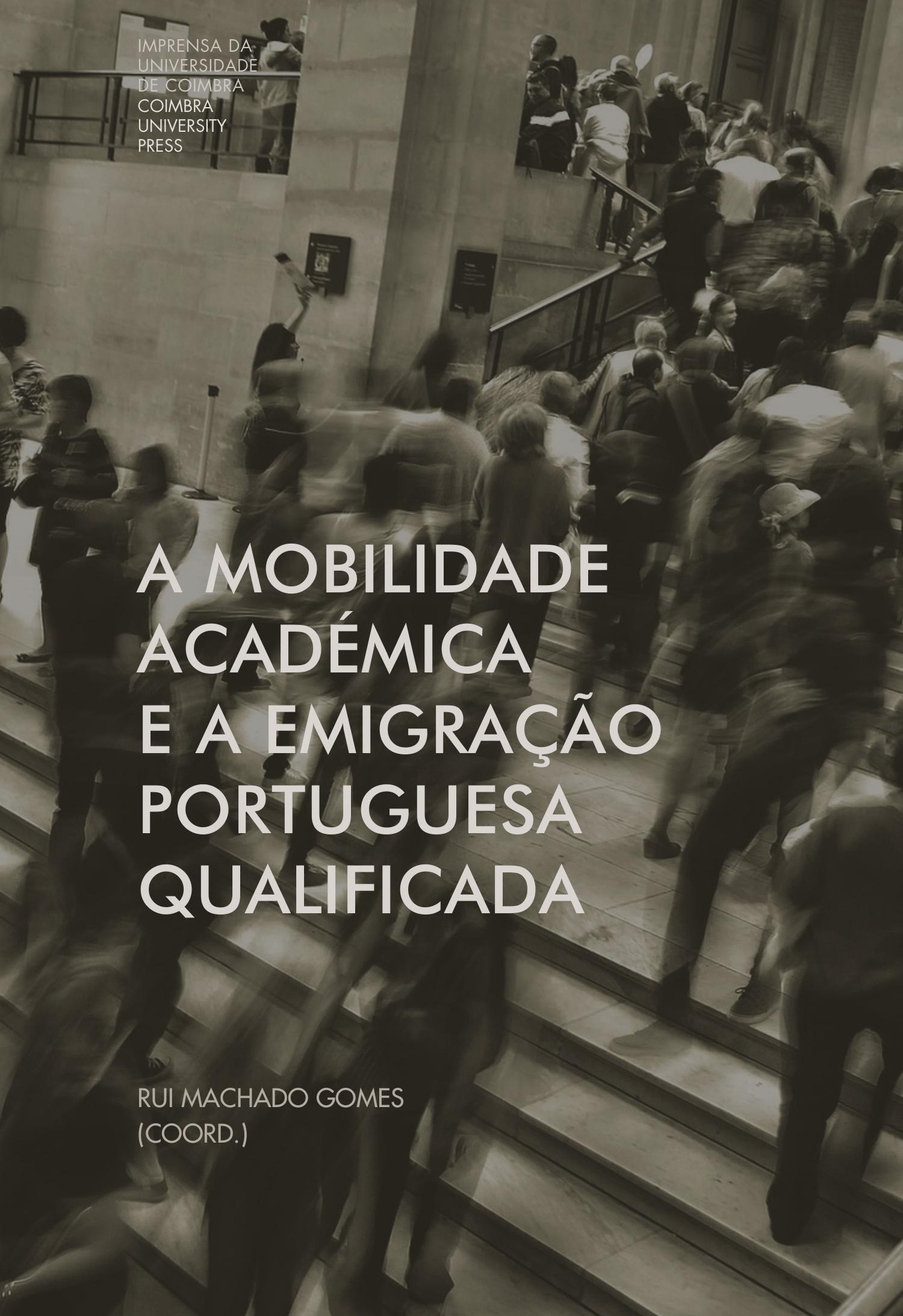


JOÃO TEIXEIRA LOPES et al. ${ }^{1}$

https://orcid.org/0000-0001-6891-7411

\section{A PRODUÇÃO SOCIAL DO INDIVÍDUO QUE EMIGRA: UMA ANÁLISEA PARTIR DE RETRATOS SOCIOLÓGICOS}

\section{Socialização e migrações: a questão da escala}

Qualquer fenómeno social pode ser estudado através de várias escalas e, preferencialmente, articulando níveis de observação. O presente texto privilegia o que poderíamos considerar a "produção social do indivíduo que decide emigrar", centrando-se nos processos e contextos de socialização que, ao longo do percurso biográfico, originam disposições sociais migratórias, conetadas ou não com processos de mobilidade social e/ou cultural, através de uma análise qualitativa, assente em 52 retratos sociológicos, metodologia proposta por Bernard Lahire (2002) e por nós atualizada (Lopes, 2014). Assim, partimos de uma amostra intencional, não aleatória, de cidadãos portugueses que estavam ou estiveram em mobilidade ou emigrados num país europeu nos últimos 6 anos, com habilitações académicas do ensino superior, ou que tivessem exercido uma atividade profissional correspondente a esse nível académico.

\footnotetext{
${ }^{1}$ Autores: João Teixeira Lopes (IS/FL - Universidade do Porto); José Pedro Silva (IS - Universidade do Porto); Rafaela Ganga (IS - Universidade do Porto); Rui Gomes (CES/ FCDEF - Universidade de Coimbra); Henrique Vaz (CIIE/FPCEUP - Universidade do Porto); Luísa Cerdeira (IE - Universidade de Lisboa); Belmiro Cabrito (IE - Universidade de Lisboa); Dulce Magalhães (IS/FLUP - Universidade do Porto); Maria Lourdes Machado-Taylor (CIPES - Centro de Investigação de Políticas do Ensino Superior); Paulo Peixoto (CES/ FE - Universidade de Coimbra); Rui Brites (ISEG - Universidade de Lisboa); Sílvia Silva (FL - Universidade do Porto/FE - Universidade de Coimbra); Tomás Patrocínio (IE - Universidade de Lisboa).

Este artigo é resultado do projeto de investigação "Êxodo de Competências e Mobilidade Académica de Portugal para a Europa" (PTDC/IVC-PEC/5049/2012), financiado por fundos nacionais através da Fundação para a Ciência e a Tecnologia (FCT/MEC) e cofinanciado pelo Fundo Europeu de Desenvolvimento Regional (FEDER) através do COMPETE - Programa Operacional Fatores de Competitividade (POFC).
} 
Esta análise insere-se num projeto vasto sobre as migrações portuguesas incluídas no fenómeno da "fuga de cérebros" ("Brain drain"). Nesse projeto, os diferentes níveis ou escalas de observação são cruzados, pelo que remetemos para outras publicações (Gomes, 2015) a evidência desse exercício.

\section{Metodologia: Perfis-tipo e retratos sociológicos}

A revisão da literatura permitiu a construção de perfis-tipo dos migrantes qualificados, de acordo com a definição de um tipo particular de relação com o fenómeno em estudo e com as hipóteses teóricas avançadas, cruzando quatro grandes princípios estruturantes: i) caraterísticas temporais da mobilidade: permanente ou temporária, de longo prazo ou transitória; ii) posição social no sistema de emprego: segmento primário ou secundário do mercado de trabalho; iii) perfil funcional no sistema de emprego: académicos e cientistas, outras profissões altamente qualificadas; iv) tipo de mobilidade: direta (depois de ter entrado no sistema de emprego do país de origem), indireta ou latente (após um período de estudo no país de acolhimento).

Os quatro perfis-tipo construídos são os seguintes:

i. migração para um país europeu para o exercício de profissões no sistema científico ou no ensino superior;

ii. migração de longo prazo para um país europeu para trabalhar no segmento primário (equivalente às qualificações académicas) ou secundário (abaixo das qualificações académicas) do sistema de emprego;

iii. mobilidade estudantil europeia, que conduz à inserção nos segmentos primário ou secundário do sistema de emprego do país em que é feita a formação;

iv. mobilidade e circulação transitória ou pendular através de redes europeias de ciência, produção, serviços ou cultura.

Em função destas categorias selecionaram-se os indivíduos a serem retratados, numa relação de 13 indivíduos por cada perfil-tipo, num total de 52 retratos. 
Os retratos sociológicos surgem como dispositivo metodológico capaz de resgatar uma dupla pluralidade nas trajetórias individuais: por um lado, a pluralidade das disposições internas, tendo em conta a sua génese, a sua desigual "força" e sistematicidade; por outro lado, a pluralidade contextual, externa, associada à multiplicidade de processos, agências e contextos de socialização ou modos de vida. Dito de outro modo: somos indivíduos plurais em contextos também eles plurais. Bernard Lahire (2002) apresenta-nos uma grande teoria capaz de corresponder à pluralidade e complexidade contemporâneas. $\mathrm{Na}$ genealogia da teoria da prática, este autor francês desenvolveu uma série de pesquisas que lhe permitiram propor um programa assente no ator plural, exposto a princípios de socialização múltiplos, diferentemente atualizado ao longo do seu percurso e fortemente relacionado com os domínios de atividade, as situações e os contextos.

Lahire (1998) chega a propor o abandono do conceito de habitus ${ }^{2}$, substituindo-o pela noção de património individual de disposições, onde se salientam, precisamente, repertórios de disposições, com géneses diferentes, graus de ativação distintos e forças diferenciadas.

$\mathrm{Na}$ verdade, um amplo trabalho de pesquisa tem demonstrado que as disposições se transferem sob um determinado número de condições. Como já referimos, existem situações que as ativam, mobilizando-as, enquanto outras as adormecem ou inibem. As próprias disposições têm graus desiguais de robustez, em íntima articulação com a sua génese (o modo particular como num determinado indivíduo o processo de socialização - sempre plural, mais ou menos contraditório e acionado por múltiplos agentes, inclusive no próprio meio familiar - se exerceu). Importa, deste modo, perceber os detalhes das variações intraindividuais, como cada indivíduo se desdobra em compromissos e metamorfoses múltiplas pelos diferentes domínios de ação.

É neste âmbito que Lahire (2002) propõe os retratos sociológicos como um dispositivo metodológico. A ideia não consiste em conceber um indivíduo isento de constrangimentos sociais, dessocializado ou fragmentado. Pelo

2 O conceito de habitus, tal como foi proposto por Pierre Bourdieu, diz respeito a um conjunto de visões do mundo e disposições para a ação coerente e inculcado, que, decorrendo do posicionamento e da trajetória do indivíduo no espaço social, estrutura as suas práticas sociais (Bourdieu, 1997). 
contrário, pretende-se analisar a sua produção social, em termos de complexidade. Afinal, o indivíduo é multissocializado e multideterminado, corpo socializado e socializador que reflete no seu percurso a arquitetura invisível das forças sociais, desenvolvendo modos de relação consigo próprio e com os contextos e situações onde se move. Essa forma de produção de si incorpora os mais pesados constrangimentos sociais e nada deve às teorias encantadas e ilusórias do livre-arbítrio. Lahire (2002) refere-se a este processo como sendo o da constituição das pregas singulares do social, advogando a autonomia e a pertinência complementares de uma escala de observação e de um nível de análise que os sociólogos não podem abandonar, sob pena de se tornarem analiticamente míopes.

Contudo, a escala de observação individual não exclui as demais: a um nível meso, encontram-se os quadros de interação e as instituições (Lopes \& Costa, 2014); a um nível macro e estrutural, estão as posições no espaço social. De certa forma, o "interior" não é mais do que um "exterior" no estado dobrado. Diz Lahire (2013, p. 16): “Não há para os indivíduos qualquer existência possível fora do tecido social (...) as fibras desse tecido, que se cruzam e entrecruzam, são constitutivas de cada indivíduo", formando, assim, uma espécie de coeficiente de singularidade. Ora, é esse coeficiente que aqui se pretende estudar: é objetivo deste artigo apreender os contextos de origem, consolidação e ativação da disposição para emigrar.

Importa salientar que, nesta pesquisa, os retratos foram sempre orientados para a(s) experiência(s) emigratória(s) dos sujeitos - não se trata de uma mera história de vida, antes do delinear de um percurso que desemboca na emigração.

\section{Uma sociografia a partir dos retratos}

Em primeiro lugar, apenas quatro dos entrevistados têm uma idade superior a 40 anos, o que mostra bem a juvenilidade da amostra: no geral, os entrevistados fazem parte dessa categoria designada de "adultez emergente" ou "jovens adultos", aprisionados no prolongamento sociológico da juventude por viverem dificuldades nos trânsitos entre ciclos de vida e passagens insti- 
tucionais (Ferreira \& Pais, 2010), amiúde não completando as transições (para a vida adulta, para o trabalho contratualizado, para uma família de destino).

Por outro lado, provêm, na sua maioria, de famílias com médio ou alto capital escolar, o que indica como forte a possibilidade de a emigração se efetuar como evitamento de processos de desclassificação social, particularmente acentuados em períodos de crise económica e social, permitindo manter ou melhorar níveis de vida, pela procura no estrangeiro de empregos mais ou menos correspondentes à formação académica. Esta, por sua vez, é elevadíssima, uma vez que 34 dos entrevistados possuem mestrado e/ou doutoramento.

Finalmente, destacaríamos, neste ponto, a escolha esmagadora de países do centro europeu, mostrando como a transferência de capital humano altamente qualificado consolida posições geopolíticas anteriores de centralidade (centro e norte da Europa) e periferia (Portugal) - muitos habitam em cidades-região fortemente integradas em sistemas urbanos de cariz transnacional.

\section{Coerências, dissonâncias, ruturas}

Comecemos por analisar a distribuição dos percursos em termos de coerência, heterogeneidade disposicional ou mesmo de rutura biográfica. De certo modo, esta análise implica uma opção artificial, se pretendermos que a classificação dos casos seja mutuamente exclusiva. Raros são os percursos que formam um património individual de disposições totalmente unificado e confirmado, contexto após contexto de socialização, ciclo de vida após ciclo de vida, incorporando a mesmidade e operando uma radical economia da contradição e da dissonância. Em todos os retratados existe algum coeficiente de diversidade disposicional, até pela multiplicidade de papéis sociais exercidos e pela plêiade de experiências vividas numa pluralidade de mundos da vida.

Deste modo, consideraremos, em termos de análise, que existe coerência disposicional quando se conjugam, mobilizam e reforçam quadros e experiências de socialização, favoráveis ou desfavoráveis, face à decisão (efetivamente tomada) de emigrar. No primeiro caso, a emigração surgirá com paixão, ou pelo menos fortemente incrustada no percurso biográfico, nas suas múltiplas 
MAPA 1: Presença dos emigrantes portugueses qualificados nas cidades de destino

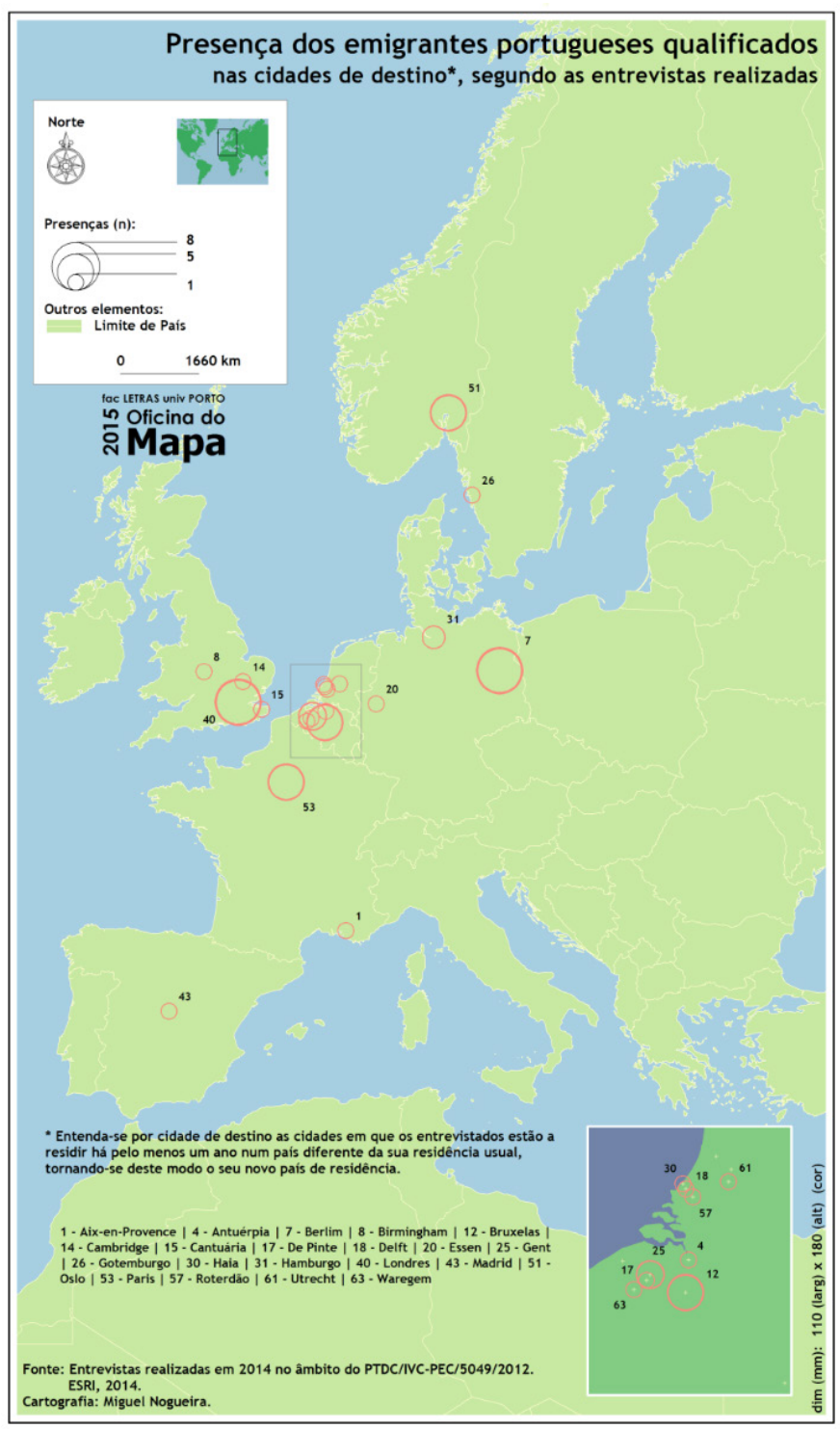


instâncias. No caso de uma coerência desfavorável, a emigração assoma com sofrimento, desgosto e/ou rejeição.

Nos casos de heterogeneidade, assistiremos a uma luta entre forças com graus diferentes de intensidade, em que as disposições mais arreigadas (porque mais precocemente interiorizadas e/ou porque mais ativa e sistematicamente mobilizadas) levam a que $o$ ator oscile, hesite ou viva com ambiguidade a sua decisão. Em percursos em que esta heterogeneidade se radicalize, poderemos encontrar situações de rutura biográfica que obrigam a escolhas, muitas vezes por inflexão de percurso, ou à resolução de impasses com maior ou menor grau de ativação de mecanismos e recursos de reflexividade.

QUADRO 1: Casos de coerência/heterogeneidade/rutura disposicional ao longo do percurso que culmina na decisão de emigrar

\begin{tabular}{|c|c|c|c|}
\hline \multicolumn{2}{|c|}{ Coerência disposicional } & \multirow{2}{*}{$\begin{array}{c}\text { Heterogeneidade } \\
\text { disposicional }\end{array}$} & $\begin{array}{c}\text { Rutura } \\
\text { biográfica }\end{array}$ \\
\hline Ana Baião & $\begin{array}{c}\text { Desfavorável } \\
\text { à emigração }\end{array}$ & Joana Batista & Manuela Alcobia \\
\hline Carlos Mesquita & & Bruno Azenha & Carlos Barradas \\
\hline Joana Antunes & Ana Taborda & Eleonora Rodrigues \\
\hline Francisco Fernandes & & Carina Faustino & \\
\hline Joana Campos & & João Sousa & \\
\hline Tiago Franco & & & \\
\hline Sónia Machado Costa & & \\
\hline Yara Reis & & & \\
\hline Alexandra Faria & & & \\
\hline Ângela Relógio & & & \\
\hline Alexandra Veríssimo & & & \\
\hline Liliana Silva & & & \\
\hline Inês Cabrito & & & \\
\hline Marisa Reis & & & \\
\hline Rita Rodrigues & & & \\
\hline Duarte Pinto & & & \\
\hline Ana da Costa & & & \\
\hline Sara Lopes & & & \\
\hline Pedro Alves & & & \\
\hline João Pais & & & \\
\hline
\end{tabular}




\begin{tabular}{|c|c|c|c|}
\hline \multicolumn{2}{|c|}{ Coerência disposicional } & \multirow{2}{*}{$\begin{array}{l}\text { Heterogeneidade } \\
\text { disposicional }\end{array}$} & \multirow{2}{*}{$\begin{array}{c}\text { Rutura } \\
\text { biográfica }\end{array}$} \\
\hline $\begin{array}{c}\text { Favorável } \\
\text { à emigração }\end{array}$ & $\begin{array}{l}\text { Desfavorável } \\
\text { à emigração }\end{array}$ & & \\
\hline \multicolumn{4}{|l|}{ Raquel Antunes } \\
\hline \multicolumn{4}{|l|}{ Amílcar Guedes } \\
\hline \multicolumn{4}{|l|}{ Firmino } \\
\hline \multicolumn{4}{|l|}{ Adriana Pereira } \\
\hline \multicolumn{4}{|l|}{ Rui C. Gomes } \\
\hline \multicolumn{4}{|l|}{ Elsa Razborsek } \\
\hline \multicolumn{4}{|l|}{ Sofia Maia } \\
\hline \multicolumn{4}{|l|}{ Nuno Saraiva } \\
\hline \multicolumn{4}{|l|}{ Sandra Antunes } \\
\hline \multicolumn{4}{|l|}{ Diana Lourenço } \\
\hline \multicolumn{4}{|l|}{ Ana Ribeiro } \\
\hline \multicolumn{4}{|l|}{ Ana Almeida } \\
\hline \multicolumn{4}{|l|}{ Cristina Nunes } \\
\hline \multicolumn{4}{|l|}{ Hugo Meneses } \\
\hline \multicolumn{4}{|l|}{ Susana Vieira } \\
\hline \multicolumn{4}{|l|}{ Pedro Barros } \\
\hline \multicolumn{4}{|l|}{ Eva Fernandes } \\
\hline \multicolumn{4}{|l|}{ Helena Sousa } \\
\hline \multicolumn{4}{|l|}{ Elisa Santos } \\
\hline \multicolumn{4}{|l|}{ Carolina Henriques } \\
\hline \multicolumn{4}{|l|}{ Fernando Carvalho } \\
\hline Vítor Martins & & & \\
\hline
\end{tabular}

Como se constata, são apenas sete os casos de heterogeneidade disposicional. Esta concentração, algo surpreendente face aos quadros teóricos de partida, demonstra a cumulatividade de certos processos sociais. Um deles reside no treino de competências de autonomia, num mútuo reforço entre família e escola. Progenitores desejosos de formarem filhos capazes de ativarem disposições contrárias a situações de dependência, libertando-os parcialmente das condições sociais de origem, em vários casos declinantes (ainda que relativamente privilegiadas), encontram em certos estabelecimentos escolares ou mesmo em programas de educação não-formal dispositivos de aprendizagem favoráveis a tal treino. 
A aquisição da autonomia processa-se por ensaios, tentativa e erro, retificação e experimentação. Neste sentido, a capacidade de agência é fortemente treinada, uma vez que os entrevistados vão revelando como aprenderam a lidar reflexivamente com os seus percursos, confrontando-se com constrangimentos vários, mas também com matrizes de escolhas e possibilidades. Um dos traços marcantes transversais a este perfil prende-se com o exercitar de projetos de mobilidade (turística, juvenil, académica, profissional), ela própria geradora de competências e disposições emancipatórias face às origens sociais.

Por outro lado, a aprendizagem relativamente precoce de disposições cosmopolitas (em cursos de línguas, viagens, programas juvenis de cooperação...), favorece claramente a decisão de emigrar para destinos densamente urbanizados, onde os entrevistados encontram atmosferas sociais e culturais que valorizam os recursos humanos qualificados no setor "quaternário" da criação simbólica e estética e nos serviços que lidam com o processamento e a difusão de informação, nas suas mais variadas formas.

Estes percursos lidam bem com as lógicas competitivas de acumulação de capital social, em particular capital social de tipo inclusivo, através do qual se articulam papéis sociais diversificados (profissional, amigo, consumidor, espetador...) localizando e otimizando recursos multilocalizados (Putnam, 2002).

Os casos de heterogeneidade, por seu lado, evidenciam o choque entre diferentes dimensões da vida na construção da disposição para a mobilidade, demonstrando, assim, a complexidade e pluralidade presentes em cada indivíduo. Para além disso, eles revelam ainda que, se a emigração trouxe consigo a possibilidade de satisfazer certas ambições, ela tem também custos produtores de um certo mal-estar. Em alguns dos casos de heterogeneidade observados, os sujeitos encontram-se numa situação profissional consideravelmente mais satisfatória do que aquela que conheciam em Portugal. Não obstante, deteta-se a expressão de um certo sofrimento, provocado por um sentimento de perda - ou, pior ainda, de abandono - de laços com pessoas significativas que ficaram em Portugal que, ainda que não seja suficientemente forte para que se lamente a decisão de emigrar, gera alguma ambiguidade. 
QUADRO 2: Contextos de ativação do processo migratório nos percursos de heterogeneidade

\begin{tabular}{|c|c|c|c|c|}
\hline Família & Profissão & $\begin{array}{c}\text { Aprendizagem } \\
\text { formal }\end{array}$ & Amigos & $\begin{array}{c}\text { Formação } \\
\text { social }\end{array}$ \\
\hline & Joana Batista & Joana Batista & Joana Batista & Joana Batista \\
\hline & Bruno Azenha & & & Bruno Azenha \\
\hline & Ana Taborda & & & Ana Taborda \\
\hline & Carina Faustino & & Carina Faustino & Carina Faustino \\
\hline & João Sousa & João Sousa & & João Sousa \\
\hline & Mafalda Costa & Mafalda Costa & & Mafalda Costa \\
\hline Catarina Gomes & Catarina Gomes & & & \\
\hline
\end{tabular}

Apesar da pressão da "formação social" (o eclodir e agudizar da crise a partir de 2008), as esferas social e afetiva jogam a sua importância na singularidade de cada percurso.

Será interessante, contudo, atentarmos mais detalhadamente nos raros casos de rutura biográfica.

QUADRO 3: Fatores e processos de rutura biográfica

\begin{tabular}{|l|l|l|}
\hline \multicolumn{1}{|c|}{$\begin{array}{c}\text { Momentos } \\
\text { (ciclo de vida) }\end{array}$} & \multicolumn{1}{|c|}{$\begin{array}{c}\text { Contextos } \\
\text { (eclosão) }\end{array}$} & \multicolumn{1}{c|}{$\begin{array}{c}\text { Mudanças } \\
\text { (disposicionais) }\end{array}$} \\
\hline $\begin{array}{l}\text { Entrada na idade } \\
\text { adulta (Daniel } \\
\text { Barradas) }\end{array}$ & $\begin{array}{l}\text { Relação afetiva (Daniel } \\
\text { Barradas) }\end{array}$ & $\begin{array}{l}\text { Sedimentação de disposições } \\
\text { cosmopolitas (Daniel Barradas) }\end{array}$ \\
\hline $\begin{array}{l}\text { Maternidade (3 } \\
\text { filhos) (Manuela } \\
\text { Alcobia) }\end{array}$ & $\begin{array}{l}\text { Contexto profissional (seu e } \\
\text { do marido); crise económica } \\
\text { (Manuela Alcobia) }\end{array}$ & $\begin{array}{l}\text { Reconstrução da carreira } \\
\text { profissional (Manuela Alcobia) }\end{array}$ \\
\hline $\begin{array}{l}\text { Relação amorosa } \\
\text { (Eleonora } \\
\text { Rodrigues) }\end{array}$ & $\begin{array}{l}\text { Inadaptação do companheiro } \\
\text { a Londres e risco de rutura } \\
\text { da relação (Eleonora } \\
\text { Rodrigues) }\end{array}$ & $\begin{array}{l}\text { Regresso a Portugal, permanência } \\
\text { temporária do casal em casa de } \\
\text { familiares e recomeço de vida } \\
\text { autónoma em Espinho (Eleonora } \\
\text { Rodrigues) }\end{array}$ \\
\hline
\end{tabular}

No percurso de Daniel Barradas existem linhas de continuidade. Uma família com algum capital escolar e focada na escolarização dos filhos favoreceu a sua dedicação aos estudos e a prossecução de hábitos de leitura e de prática musical, que o levaram a seguir estudos musicais, contra vontade, 
e depois design gráfico, em Lisboa. Tudo parecia encaminhado para uma internacionalização pela porta grande, em Nova Iorque, mas fez a escolha "menos lógica", rumando à Noruega, a convite do namorado que acabara de conhecer. A partir daí, o contacto com a realidade laboral norueguesa, em vários empregos ligados ao design, a inserção em redes "gay" e as inúmeras situações de abertura à diversidade consolidaram fortes disposições cosmopolitas. Regressou a Portugal com o namorado, devido a ter resvalado para uma situação de subemprego, mas a crise de 2008 fá-lo regressar à Noruega, onde encontrou novo relacionamento que resultou mais tarde em casamento. Hoje, mesmo não se sentindo profissionalmente seguro, não vislumbra qualquer possibilidade ou desejo de regresso, dada a proteção social que a Noruega lhe oferece. Esta perceção vincada de um regresso improvável, associada à idade madura, torna-o nostálgico, o que mostra bem como as disposições cosmopolitas podem coexistir com inclinações saudosistas.

No caso de Manuela Alcobia, a disposição para emigrar resulta de uma situação de rutura, produzindo ela própria reajustamentos subsequentes. Antes de partir, Manuela estava empregada há treze anos num hospital público, trabalhando como técnica de saúde para diagnóstico genético. No entanto, a impossibilidade de progressão na sua carreira na função pública, a que não são indiferentes as políticas de austeridade adotadas em Portugal, associada à instabilidade no trabalho do marido, com salários em atraso, obrigaram-na a optar entre a emigração ou um ajustamento do estilo de vida face à nova realidade económica familiar. Escolhendo a primeira opção, toda a família emigrou para Londres de forma planeada. No Reino Unido vivem com boas condições financeiras, mas com algum sofrimento pelos laços deixados em Portugal. Manuela retrocedeu - momentaneamente, pelo menos - do ponto de vista da carreira e do reconhecimento profissional e reconhece ter agora menos espaço para ser criativa no trabalho. Por outro lado, gosta do papel que a confiança tem nas relações laborais e considera estarem reunidas melhores condições para ajudar os três filhos a construir um futuro.

Finalmente, Eleonora Rodrigues, com 31 anos, é natural de Lisboa e vive em Espinho. Tanto o pai (bacharel da Escola do Comércio) como a mãe (12. ${ }^{\circ}$ ano) nasceram em Angola, para onde as respetivas famílias tinham ido viver. Após uma passagem de 3 anos pelo Brasil, iniciada quando Eleonora tinha 
apenas três meses, o casal conheceu uma situação difícil quando, já em Portugal, a empresa de importação/exportação que entretanto fundara faliu. Aos 16 anos, Eleonora vivia e estudava em Coimbra com a irmã mais velha, quando os pais se mudaram para Leiria por razões profissionais. Tal contribuiu para que adquirisse desde cedo uma certa autonomia. Licenciou-se em Comunicação Organizacional na Escola Superior de Educação de Coimbra e fez Erasmus em Istambul, experiência rica em novas aprendizagens e sociabilidades e decisiva para reforçar a vontade de conhecer o mundo. Terminada a licenciatura, e depois de alguns estágios não remunerados e trabalhos precários, conseguiu uma ambicionada experiência profissional internacional através do programa INOV Contacto: um estágio de 9 meses no Brasil, na área de assessoria e gestão de eventos. De volta a Portugal, conheceu o atual companheiro e foi viver para Espinho, terra natal dele. Trabalhou 9 meses como assistente de marketing e de direção, seguindo-se uma curta experiência como vendedora de máquinas Bimby. Face à precariedade da vida profissional de ambos, e apesar de alguma resistência dele, o casal emigrou para Londres em janeiro de 2013, destino escolhido pela língua inglesa e por ele ter um casal amigo em Inglaterra. Eleonora encontrou trabalho, orientado para o mercado brasileiro, como Advertising Sales Executive; mas descobriu que o seu chefe - um português - pagava salários inferiores aos trabalhadores oriundos de Portugal, Espanha e América Latina. Para além disso, o companheiro não se adaptou a Londres, o que gerou um mal-estar emocional. Três meses depois da chegada e com a sua relação em risco, o casal decidiu voltar a Portugal, vivendo temporariamente em casa dos pais dele. Eleonora encontrou um estágio profissional de um ano, sem qualquer possibilidade de continuidade, voltado para o mercado brasileiro. Manifesta descontentamento com o elitismo do ensino superior, a precariedade do mercado de trabalho e as políticas públicas de emprego. Voltar a emigrar é uma hipótese que não descarta.

\section{Notas conclusivas}

Antes de mais, importa referir uma surpresa na análise dos resultados: não esperávamos encontrar tantos casos de coerência disposicional favorável à 
emigração. Insistimos num ponto: não estamos a falar de percursos monolíticos, nem de indivíduos despojados de pluralidade (de princípios de socialização, papéis e experiências sociais ou mesmo patrimónios de disposições). Contudo, parece claro que a emigração surge como consequência de um reforço entre disposições favoráveis à autonomia, emancipação e cosmopolitismo (contacto precoce com o universo das viagens e das diferenças culturais), a influência de outros significativos nos processos de socialização (pais, familiares, professores, amigos) e, em muitos trajetos, a vivência de experiências de mobilidade estudantil (Erasmus). Esta conjugação é acicatada quer pela vontade de concretizar aspirações e projetos (em que frequentemente se cruzam motivos amorosos e profissionais), quer pela constatação de uma ausência de contextos de ativação de disposições e competências qualificadas em Portugal. A dissociação entre percursos académicos bem-sucedidos e altamente qualificados e o mercado de trabalho nacional, incapaz de absorver estes recursos, gera um efeito de procura de realização profissional num contexto internacional, o qual passa a ser percebido como um mercado global.

Os casos de heterogeneidade evidenciam a potencial colisão entre diferentes esferas da vida, jogando com a força que cada uma delas desempenhava na singularidade dos percursos.

Finalmente, as trajetórias de rutura denotam bifurcações biográficas, com reajustamentos significativos. Num caso, evidencia o predomínio de lógicas afetivas (Carlos Barradas), noutro a recusa em aceitar uma abrupta queda social (Manuela Alcobia).

Esta é uma síntese possível, resultado do olhar comparativo entre trajetos. Contudo, gostaríamos que ela não descartasse a ideia da multiplicidade de casos e de percursos, percebendo como, em cada indivíduo, se cruzam de forma singular, única e irrepetível múltiplas influências socializadoras, processos e dinâmicas sociais, experiências e momentos. Assim, importa ainda sublinhar a potencialidade do retrato sociológico enquanto dispositivo metodológico, não sendo displicente afirmar que este dispositivo metodológico permite captar, por um lado, a complexidade das sociedades contemporâneas, através da análise transversal e comparativa e, por outro lado, a natureza plural dos projetos de vida, através da prática de uma sociologia ao nível do indivíduo. 


\section{Referências Bibliográficas}

AA.VV. (17 de maio de 2011). Memorando da troika anotado. Público. Disponível em http://www.publico.pt/economia/memorando-da-troika-anotado

BEINE, M., Docquier, F., \& Rapoport, H. (2008). Brain Drain and Human Capital Formation in Developing Countries: Winners and Losers. The Economic Journal, 118(528), 631-652.

BOURDIEU, P. (1997). Razões Práticas - Sobre a Teoria da Acção. Oeiras: Celta.

FERreIRA, V. S., \& Pais, J. M. (2010). Tempos e Transições de Vida: Portugal ao Espelho da Europa. Lisboa: Imprensa de Ciências Sociais.

LAHIRE, B. (1998). L'Homme pluriel. Les ressorts de l'action. Paris: Nathan.

LAHIRE, B. (2002). Portraits Sociologiques. Paris: Nathan.

LAHIRE, B. (2013). O Singular Plural. Cadernos do Sociófilo, Quarto Caderno, 16-26.

LOPES, J. T. (2014). Retratos sociológicos: dispositivo metodológico para uma sociologia da pluralidade disposicional. In L. L. Torres, \& J. A. Palhares, Metodologia de Investigação em Ciências Sociais da Educação. V. N. de Famalicão: Húmus.

LOPES, J. T., \& Costa, A. F. (2014). Estrutura, contexto e agência nos percursos desiguais dos estudantes do ensino superior: Fatores e processos de sucesso e insucesso. In A. F. Costa, J. T. Lopes, \& A. Caetano, Percursos de Estudantes no Ensino Superior (pp. 203-210). Lisboa: Editora Mundos Sociais.

MALHEIROS, J. (31 de março de 2011). JANUS.NET e-journal of International Relations, 2(1), 133-142. Disponível em: http://.ual.pt/janus.net/pt_vol2_n1_(Consultado em: 31 novembro 2013).

MATTOO, A., Neagu, I. C., \& Özden, C. (2005). Brain Waste? Educated Immigrants in the U.S. Labor Market. World Bank Policy Research Working Paper No. 3581). Washington, DC: World Bank.

PIRES, R. P., Pereira, C., Azevedo, J., Santo, I. E., \& Vidigal, I. (16 de Março de 2015). Portuguese Emigration Factbook 2014. Obtido de Observatório da Emigração: http://www.observatorioemigracao.pt/np4/1269 